\title{
Schweißtechnik im Wandel
}

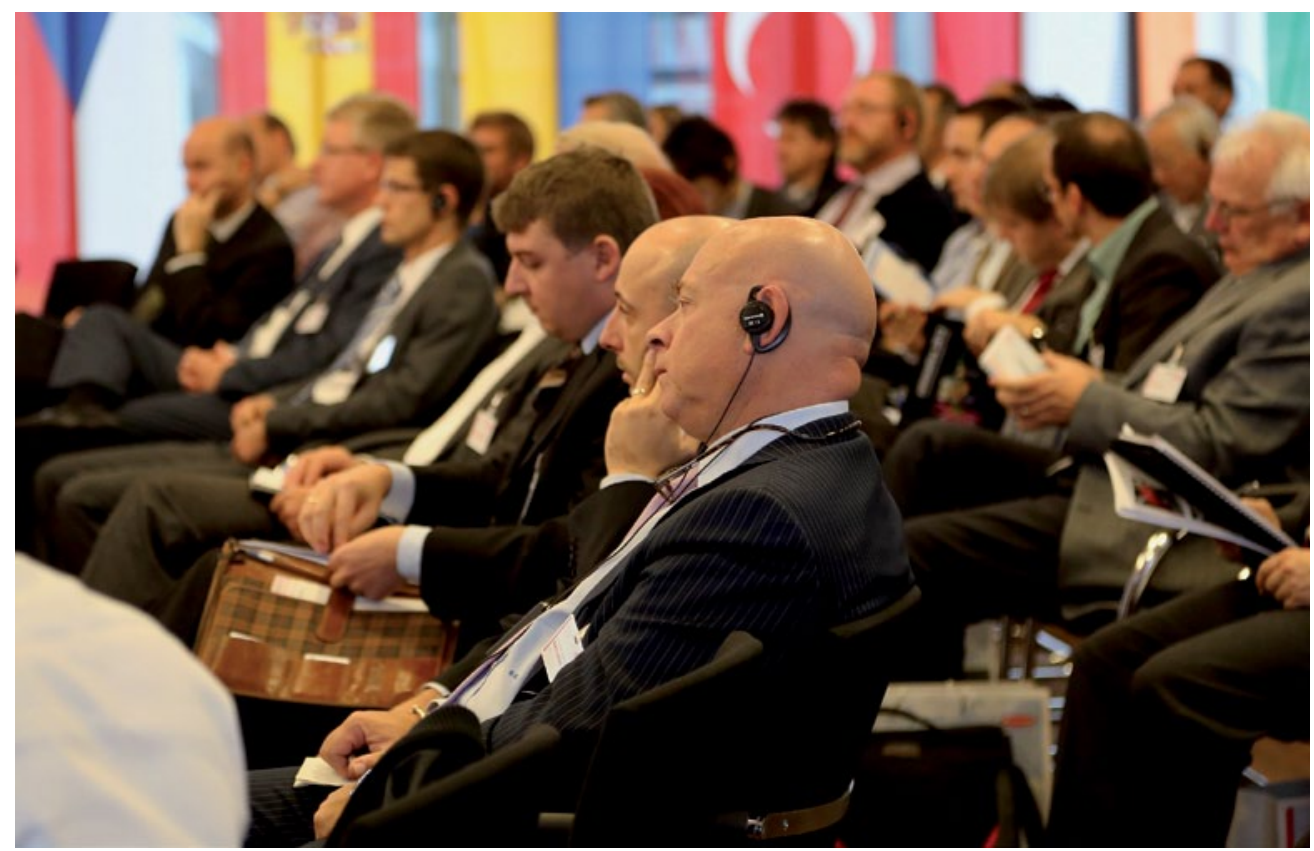

karosserie über 85 m Klebenaht und wird zudem mit 778 Stanznieten und 465 selbstfurchenden Schrauben zusammengehalten.

Dabei ist der Karosseriebau nur eine Baustelle, wenn es um die Weiterentwicklung der Schweißtechnik geht. Auch die Fahrwerktechnik, bislang eine Domäne für das Lichtbogenschweißen, bietet ein vielfältiges Innovationspotenzial. Doch um das Laserhybridschweißen vollautomatisiert einsetzen zu können, bedurfte es beispielsweise bei Daimler nicht nur Weiterentwicklungen in der Schweißtechnik selbst, sondern auch der Einführung einer digitalen Absicherung der Bauteile, der Ent-

Die zunehmende Verästelung der werkstofflichen Leichtbaumaßnahmen im Automobilbau gerät mehr und mehr zum Innovator und Ideengeber für die Fügetechnik. Anlässlich der von Fronius veranstalteten 3. Internationalen Konferenz Fügetechnische Herausforderungen im modernen Automobilbau diskutierten 120 Experten Status und Ausblick.

Wie sehr sich die Werkstoffwahl auf die Komplexität der Fügetechnik auswirkt, zeigt der Vergleich zweier Fahrzeuge, deren verbindungstechnische Besonderheiten im Rahmen der Tagung präsentiert wurden. Da ist zunächst der neue BMW 1 er, der in den Werken Regensburg, Leipzig und bald auch in China vorwiegend aus verschiedenen Stahlsorten gefertigt wird. So sieht das Werkstoffdiagramm für den Fünftürer für die Karosserie einen Gewichtsanteil von $58 \%$ an hochfesten Stählen, $20 \%$ konventionellen Stählen, $16 \%$ Mehrphasenstählen, $3 \%$ pressgehärteten Stählen und nur $3 \%$ anderer Werkstoffe vor.
Entsprechend übersichtlich gestaltet sich der Karosseriebau. Dieser nutzt 5550 Schweißpunkte, 0,86 m Schutzgasschweißnaht, 2,6 m Laserschweißnaht, 49,5 m Klebenaht, 229 Bolzen und 44 Schrauben.

Ganz anders stellt sich die Situation beim Konzeptfahrzeug Cult von Magna Steyr Fahrzeugtechnik dar. Im Bemühen um einen Zielwert von $49 \mathrm{~g} \mathrm{CO}_{2}$ bei einem Zielpreis von maximal 17.000 Euro griffen die Entwickler tief in die leichtbauwerkstoffliche Trickkiste. So weist das Gewichtsverteilungsdiagramm für die Rohkarosserie nur $7 \%$ Stahl aus. $17 \%$ entfallen auf Aluminiumguss, $26 \%$ auf Aluminiumblech und $27 \%$ auf Aluminiumprofile. Dazu kommen $5 \%$ Sandwichbauteile, $8 \%$ duroplastische Kohlefaserkomposites sowie $10 \%$ thermoplastische Glasfaserkomposites.

Diese Werkstoffvielfalt spiegelt sich auch in der Verbindungstechnik. Mit gerade einmal 14 m Schweißnaht, ausgeführt in CMT-Technik, ist das Schweißen deutlich unterrepräsentiert. Dafür verfügt die Roh- wicklung von Prozessarmrobotern sowie einer grafischen Programmkorrektur zur Online-Optimierung der Schweißnähte. Lohn der Mühe: ein konzentrierter Wärmeeintrag mit definierter Einschweißtiefe beziehungsweise Schweißgeschwindigkeit, eine hohe Prozessstabilität sowie eine hohe Reproduzierbarkeit der Schweißqualität.

Um im härter werdenden Wettbewerb zwischen thermischen, mechanischen und chemischen Fügeverfahren die Nase vorne zu behalten, kündigte Fronius-Entwicklungschef Heinz Hackl am Rande der Tagung mehrere Weiterentwicklungen an. Vor allem die Doppeldrahttechnik werde ausgeweitet. Die Neuentwicklung „CMT Twin", die es Anwendern erlaubt, zwei Cold-Metal-Transfer-Prozesse (CMT) oder eine Kombination aus einem CMT-Prozess und einem Pulsschweißprozess in einem System zu nutzen, sei erst der Anfang. Ein großes Potenzial für Verbesserungen sieht Hackl auch im Bereich von Kurzlichtbogen.

hlo 